\title{
Economías de aglomeración en servicios hoteleros: Los casos de Acapulco, Guerrero y Boca del Río Veracruz en México
}

\author{
Bracamonte Jaraba, Melissa Andrea \\ Universidad Autónoma de Guerrero, México \\ melissabracamonte30@gmail.com \\ Astudillo Miller, María Xochitl \\ Universidad Autónoma de Guerrero, México \\ xmiller@live.com.mx
}

\author{
Hernández González, Darío F. \\ Universidad Veracruzana, México \\ darhernandez@uv.mx
}

Resumen - Se presenta una interpretación y análisis comparativo de las aglomeraciones hoteleras en Acapulco y Boca del Río, abarcando un estudio del desarrollo económico - turístico. El análisis se basa en información obtenida del INEGI a través del DENUE y Mapa Digital. El estudio reveló que los hoteles se agrupan alrededor de las costas teniendo como foco de atracción la playa, esto ha dado lugar a otras aglomeraciones que benefician a la industria hotelera pero también contribuyen a esta.

Palabras claves - economías de aglomeración; industria hotelera; aglomeración Acapulco; aglomeración Boca del Río.

Abstract - An interpretation and comparative analysis of the hotel agglomerations in Acapulco and Boca del Río is presented, covering a study of the economic - tourist development. The analysis is based on information obtained from the INEGI through the DENUE and the Digital Map. The study revealed that hotels are grouped around the coasts with the beach as the focus of attraction, this has given rise to other agglomerations that benefit the hotel industry but also contribute to it.

Keywords - agglomeration economies; hotel industry; Acapulco agglomeration; Boca del Río agglomeration.

\section{INTRODUCCIÓN}

Las economías de aglomeración se caracterizan por poseer una evidente y numerosa población cuyo patrimonio intangible y material es abundante, constituye su fuente de empleo y modo de vida primordial, pero también y por ello; son altamente vulnerables a perder su forma de vida (economía, cultura y tradición). Una economía de aglomeración es, como su nombre lo in- 
dica, una concentración o agrupación geográfica de prestadores de servicios, productores y/o pequeñas empresas "que entre mayor sea su asociación horizontal y vertical en una o varias fases de la producción de un bien o servicio, mayor es su importancia relativa a una red productiva (Hernández, 2014).

Sin embargo, pese a todas las bondades de las economías de aglomeración, como la generación de economías de escala y mayor especialización del trabajo, las aglomeraciones no generarán mayores beneficios al sector empresarial y a la ciudad si no son organizadas y planeadas adecuadamente. Este escrito se plantea realizar un análisis comparativo de las economías de aglomeración de los hoteles que pertenecen a Boca del Rio en Veracruz y Acapulco en Guerrero con la finalidad de entender las razones por las cuales los hoteles en ambas ciudades se agrupan en una misma zona y que externalidades ha generado el hecho de aglomerarse, para realizar este análisis se utilizaron los mapas digitales de INEGI que permitieron ver la ubicación de los hoteles en el mapa de cada ciudad.
El documento se estructura de la siguiente forma. Inicialmente se estudia la dinámica de las economías de aglomeración conociendo los tipos que existen y las formas de organización espacial de las empresas; seguido a esto se indaga el desarrollo económico-turístico de Acapulco y Boca del Rio; en tercer lugar se realiza un análisis de la aglomeración hotelera en los municipios estudiados dando una mirada retrospectiva a esta durante los años 2011 al 2016 y observando otras aglomeraciones derivadas de la hotelera para dar paso a los comentarios finales sobre este estudio.

\section{LA DINÁMICA DE LAS ECONOMÍAS DE AgLOMERACIÓN}

La aglomeración en las ciudades es la concentración espacial de la actividad económica que también puede tomar la forma de concentración en centros de empleo en una ciudad o en grupos industriales (WiIliam Strange, 2005). Recientemente se ha empezado a considerar la organización espacial de la producción como un mecanismo estratégico y determinante en 
los procesos de desarrollo económico (Barquero, 2006). De manera general, las economías de aglomeración se clasifican en tres tipos: economías internas a la empresa, economías de localización y economías de urbanización. Las primeras hacen referencia a la concentración de la producción en una única empresa, las segundas según Marshall (1990) se relacionan con la concentración en industrias particulares y las últimas de acuerdo a Jacobs (1969) con el tamaño o la diversidad de la ciudad (Manrique, 2006).

Existen diversas formas de economías de aglomeración, en este documento ahondaremos en dos importantes tipos de aglomeración que son los distritos industriales $y$ los clusters. Dei Ottati (1987) menciona que el distrito industrial está conformado por pequeñas y medianas empresas de dimensiones modestas tanto en el monto de sus inversiones como en personal ocupado, con una organización interna simple y una gestión empresarial familiar o individual; en las empresas que pertenecen a los distritos industriales no existe diferencia entre el rol del empresario y el del tra- bajador. Estas firmas se agrupan en un ámbito geográfico acotado y se insertan productivamente a través de la realización de operaciones individuales de un proceso productivo genérico; es decir, no elaboran productos finales completos sino que se especializan de unas pocas fases de un proceso productivo mucho más amplio (Quintar \& Gatto, 1992, pág. 11).

Lo interesante de esta tipología de aglomeración es que se basan en un modelo de trabajo cooperativista en el cual las empresas están tan cohesionadas que actúan como una unidad de modo que si es afectada una, son afectadas todas y si se beneficia una, se benefician todas. En este sentido, los distritos industriales actúan como un conjunto y como un sistema que trabaja aliado a las cámaras, bancos, asociaciones civiles, gubernamentales, instituciones de investigación y cooperativas con la finalidad de incrementar no solo el nivel de competitividad y desarrollo de un grupo de empresas, sino de la ciudad donde están asentados y en ese sentido trabajan por el desarrollo de la economía local bajo el principio de la cooperación y la compe- 
tencia: "Coopetencia", buscando siempre que la ciudad donde operan prospere porque de este modo prosperaran las empresas también.

Los distritos industriales se caracterizan porque tienen tradición y transferencia generacional y territorial del conocimiento formal e informal; son un conglomerado de empresas concentradas geográficamente y especializadas sectorialmente; se dividen por fases de la cadena de valor; generan confianza en la negociación; tienen un fuerte desempeño organizativo en el cual las alianzas estratégicas son fundamentales para su desarrollo; son flexibles laboral y productivamente, por lo que se adapta con mayor facilidad al entorno global; tienden a generar intercambio de bienes, trabajo e información por medio de los mercados o fuera de ellos; crean una reputación colectiva dando lugar a patentes y las empresas que pertenecen a un distrito industrial comparten una misma visión. Es importante tener en cuenta que para que haya desarrollo económico con base en el distrito industrial es necesario que haya también innovación en la trasformación productiva así como en los sistemas de comu- nicación y los sistemas de administración; especialización productiva en sectores dinámicos y asociatividad.

Por su parte los clusters, al igual que el distrito industrial, son un modelo de organización de la producción que supone un enfoque del desarrollo económico que reconoce un papel fundamental a la localización territorial, al igual que las otras formas de aglomeración. De acuerdo con Porter, los clusters son concentraciones geográficas de empresas interconectadas, proveedores especializados, entidades suministradoras de servicios en actividades relacionadas e instituciones asociadas como universidades, asociaciones de comercio y otras. Estos se centran en la búsqueda de las fuentes de ventajas competitivas de los agrupamientos sectoriales de empresas situados en distintos lugares o territorios (Alburquerque, 2006).

El surgimiento de un cluster en un territorio puede explicarse por distintas razones. Una se relaciona con las ventajas existentes de algunos factores, tales como clima, recursos naturales, yacimientos 
minerales, rutas de transporte, puertos, entre otros. Es el caso de los clusters alrededor de 11 recursos naturales, donde su localización puede explicarse mayormente por la geografía de los factores de producción. Otra explicación se refiere a "accidentes" históricos, como la presencia de una masa crítica de emprendedores exitosos y/o la existencia de recursos humanos capacitados que confluyen en un territorio determinado. Esta situación suele presentarse con mayor frecuencia en los sectores industriales. Para que los clusters prosperen se necesitan varios elementos, incluyendo la sofisticación de la demanda, la mejora y especialización de los factores, la construcción de estrategias de competencia y cooperación, las condiciones institucionales que favorezcan la difusión del conocimiento y la innovación, así como políticas promotoras y facilitadoras del desarrollo (Sagarpa \& FAO, 2013).

Los clusters son de tipo anglosajón y se enfocan principalmente en ser competitivos no importando tanto como se logre sino lograrlo y aunque es importante para una em- presa que a las otras organizaciones pertenecientes a esta aglomeración les vaya bien, no actúan como un sistema ya que cada unidad productiva debe buscar la forma de lograr la competitividad. Una característica importante de los clusters es que estos son creados artificialmente mientras que los distritos industriales provienen de la historia, la tradición y la transferencia generacional.

\section{DESARROLLO ECONÓMICO - TURÍSTICO EN ACAPULCO Y BOCA DEL RÍO}

El sector turístico se ha convertido, en pocos años, en uno de los sectores de actividad fundamentales del desarrollo económico de muchos países, y ha influido, de forma determinante, en los cambios sociales, económicos y culturales que se están produciendo en la sociedad en general (Rodríguez Domínguez, 2001). Sin duda es uno de los sectores económicos más importantes y dinámicos en el mundo actual, tanto por su nivel de inversión, participación en el empleo, aportación de divisas, como por la contribución al desarrollo regional ya que aporta directamente el $10 \%$ del PIB mundial y genera uno de cada diez em- 
pleos. De hecho la organización Mundial del Turismo estima que para el año 2030 se alcanzará la cifra de mil ochocientos millones de turistas internacionales en el mundo (Secretaría de Turismo de México, 2018), de ahí que este sector sea para muchos países prioritario, entre ellos México.

México es el tercer país más grande de América latina, el decimocuarto más extenso del mundo y el undécimo más poblado a nivel global. Para el año 2015 México fue considerado por la Organización Mundial del Turismo como el principal destino turístico de América Latina y el octavo más visitado del planeta (World Tourism Organization, 2015) sus ciudades coloniales, gastronomía, la calidez de su gente, hermosas playas, su legado histórico - cultural y la conjugación de culturas como la europea y la mesoamericana hacen de este país una joya turística tan cautivante que no se puede ignorar.

Para la economía mexicana la importancia del turismo es incuestionable, este sector generó cuatro millones noventa y cinco mil em- pleos directos en el año 2017, lo que representó $8.6 \%$ del empleo total y un incremento del $3.6 \%$ en el cuarto trimestre de este año con respecto al mismo periodo del 2016 (Sistema de Información de Estadísticas Turísticas - DATATUR, 2018). Sus beneficios no solo se reflejan en ser una industria que genera empleo y en ser un detonador del desarrollo local y regional, sino que además es factor de difusión de atractivos culturales y naturales. Según lo afirma el Banco de México, la llegada de turistas internacionales incrementó en el 2017 con relación al 2016 en un $12 \%$ y los ingresos por estos visitantes internacionales aumentaron al $8.6 \%$ (Secretaría de Turismo de México, 2018), este acrecentamiento evidencia como cada vez más personas alrededor del mundo prefieren a México como destino turístico, esto se convierte en una gran oportunidad, pero también en un reto que tiene el país de generar e implementar estrategias en favor del desarrollo de la actividad turística y el incremento de la competitividad de este sector, para alcanzar así un mejor posicionamiento en el ámbito global. 
Lo que es un hecho es que varios estados y municipios en México viven en gran parte del turismo, uno de estos estados es Guerrero. El estado de Guerrero se localiza en el suroeste de la república mexicana, limita al norte con el estado de México y Morelos, al sur con el océano pacifico, al este con Oaxaca, al noroeste con Michoacán y al noreste con Puebla. Sus sectores estratégicos son la agroindustria, minería y turismo, la entidad cuenta con cinco puertos, cuatro de ellos cuya actividad preponderante es la turística (Concanaco Servytur México, 2017). Este estado cuenta también con importantes destinos turísticos que en su conjunto son conocidos como el Triángulo del Sol y lo conforman Taxco, Ixtapa Zihuatanejo y Acapulco. Taxco, un hermoso pueblo mágico ubicado al norte del estado, en la zona centro del país, atrayente por su estilo virreinal, sus minas de plata, sus construcciones coloniales y sus encantadores paisajes; por su parte Ixtapa-Zihuatanejo es un resort de playa que se encuentra ubicado en el municipio de Zihuatanejo de Azueta, este es un destino planeado y diseñado que muestra modernismo y clase, cuenta con una variedad de hoteles, así como una isla en la cual se podrá encontrar gran diversidad de especies animales; Finalmente está la ciudad de Acapulco que es considerada como el destino turístico más importante de Guerrero.

Acapulco es la ciudad más poblada de Guerrero, se divide en tres grandes zonas turísticas conocidas como Acapulco Tradicional, Acapulco Dorado y Acapulco Diamante. El auge de esta ciudad inicio en los años cincuenta cuando estrellas de televisión y cine se paseaban por sus calles a plena luz del día, así como, magnates, hombres de negocios y artistas de todo el mundo elegían lujosas mansiones en esta ciudad (SECTUR, 2014), gracias a esto Acapulco contribuyó a que México fuese conocido en el ámbito global como un país con potencial turístico. Sin embargo, a pesar del apogeo que tuvo Acapulco, actualmente esta ciudad no maneja el mismo flujo de turistas, principalmente internacionales, que manejaba algunos años atrás, esto se debe a la percepción que se tiene de Acapulco como destino inseguro y esta percepción es cada vez más generalizada. Actualmente, 
los turistas que más llegan a Acapulco provienen de la Ciudad de México, en parte por la cercanía entre ambas ciudades. Para Agustín González, representante de la Asociación Nacional de Agencias de Viajes, los viajeros de la Ciudad de México continúan visitando el destino a pesar de la situación porque ya saben vivir con el fenómeno de la inseguridad $y$ porque se han mantenido los precios cuando han debido subir como en otros destinos (CONCANACO SERVYTUR, 2017).

No obstante, en la actualidad Acapulco sigue siendo un lugar atrayente para el turismo nacional. Pese a todos los problemas que le atañen, esta ciudad posee diversos atractivos que enamoran a sus visitantes como su clima tropical durante todo el año; su mar cálido de un brillante y transparente azul que permite apreciar el paisaje subacuático; su arena dorada; su vida nocturna; tradiciones como el Jueves Pozolero que convierte este día en celebración para los acapulqueños; la gastronomía de la ciudad de la cual resalta su plato típico, el pescado a la talla y sitios que le han otorgado fama como La
Quebrada; estos cuatro últimos aspectos son sin duda elementos de identidad para Acapulco.

Para la economía de Guerrero, Acapulco juega un papel fundamental, en el año 2016 representó el $44.5 \%$ del total de ingresos del estado (Concanaco Servytur México, 2017), gran parte de esos ingresos provienen del turismo, al ser esta la actividad económica más importante de la ciudad y el estado en general. Es necesario tener en cuenta que un sector crece y aumenta su nivel de importancia cuando los subsectores que hacen parte de este crecen también y un subsector importante en la cadena de valor del turismo es la industria hotelera.

Para México los hoteles son un eslabón importante dentro de su actividad turística ya que su desarrollo como industria, incide en el desarrollo del sector turístico. De acuerdo con cifras que reveló DATATUR el primer puente vacacional de 2018 registró un máximo histórico de llegadas de turistas nacionales a cuartos de hotel que pasó de 967.004 en 2015, a 1 millón 64 mil 331 visitantes (Secretaría de Turis- 
mo, 2018). Acapulco en particular, cuenta con 19 mil cuartos de hotel y unos 40 mil lugares más como oferta extra entre apartamentos y casas para arrendar (CONCANACO SERVYTUR, 2017). Durante el 2016 Acapulco registró un hospedaje de 5.6 millones de turistas, lo que lo ubicó como el tercer destino con más turistas hospedados en hoteles, superado solo por la Ciudad de México y Cancún (Secretaría de Turismo, 2017).

Otro estado para el cual el turismo es un sector de gran relevancia es Veracruz de Ignacio de la Llave, ubicado al este del país limita al norte con Tamaulipas, al noroeste con San Luis Potosí, al sur con Oaxaca, al sureste con Tabasco y Chiapas al este con el Golfo de México y al oeste con Puebla e Hidalgo. Veracruz es un estado que cuenta con importantes destinos turísticos de los que se pueden destacar Orizaba, ideal para el turismo ecológico; el Puerto de Veracruz, lleno de cultura e historia y Boca del Río, perfecto para el turismo de sol y playa. En cuanto a la llegada de turistas, Veracruz recibió 5.699 .743 en 2014 , en 2015 esta ci- fra bajó a 5.440 .578 y para 2016 recibió 5.192 .572 turistas (DATATUR, 2017). Las anteriores cifras muestran un decrecimiento en la llegada de turistas tanto nacionales como internacionales a pesar de ser este un lugar encantador que ofrece una amplia biodiversidad, maravillas naturales, ciudades coloniales, una riqueza cultural e histórica fascinante y lugares agradables para el turismo, como lo es Boca del Río.

Boca del Río es una localidad ubicada al sur del Puerto de Veracruz, con el cual se encuentra conurbado, está situada a un costado del mar y el río Jamapa; en algún tiempo esta fue una población de pescadores, actualmente es un lugar ideal para el turismo gracias a sus hermosas playas de una fina arena color plata; su gastronomía que posee prestigio gracias a deliciosas preparaciones entre las cuales se pueden destacar su filete relleno de mariscos, el arroz a la tumbada, y camarones al coco; el modernismo en su desarrollo urbano y en la prestación de servicios y el encanto y hospitalidad de su gente. Boca del Río es sin lugar a 
Bracamonte Jaraba, Melissa Andrea; et al

dudas uno de los destino más importantes en cuanto a turismo para el estado de Veracruz, según un estudio realizado en 2015 por la Secretaria de Turismo, BBVA Data \& Analytics y BBVA Bancomer se encontró que de los destinos de Boca del Río, Orizaba y Veracruz, Boca del Río reportó el mayor volumen de gasto por parte de los turistas nacionales (Sectur, BBVA Data \& Analytics, BBVA Bancomer, 2015).

La industria hotelera en Boca del Río ha avanzado conforme lo ha hecho está localidad, en la actualidad se está desarrollando un cluster turístico que integra y organiza a las empresas pertenecientes a este sector como lo son los hoteles, y la ciudad cuenta con hoteles de diversas categorías que procuran mantener estándares de calidad para la satisfacción de sus clientes.

\section{ANÁLISIS DE LA}

\section{AglOMERACIÓN Hotelera EN} ACAPUlCO Y BoCA DEL RÍO

Para realizar el análisis de la aglomeración hotelera fue necesaria la herramienta Mapa Digital de México del Instituto Nacional de Estadística y Geografía de México -INEGI- que es un sistema de información geográfica que integra datos estadísticos de múltiples bancos de datos georreferenciados ofertados por el INEGI, destacando para el caso del presente estudio los elementos naturales y culturales que conforman el entorno geográfico de los destinos elegidos, Acapulco y Boca del Río, y permite relacionarlo con información estadística.

Para poder observar las unidades económicas al interior del mapa se utilizó el Directorio Estadístico Nacional de Unidades Económicas -DENUE- que ofreció los datos de identificación, ubicación, actividad económica y tamaño de los negocios activos en los territorios estudiados (Instituto Nacional de Estadística y Geografía, s.f.). Una vez que se obtuvo el DENUE y se descargó el Sistema Mapa Digital de México, se buscó en el sitio oficial del INEGI el mapa topográfico de las ciudades analizadas y se insertó junto con la información de las industrias estudiadas en la plataforma Mapa Digital de México, esto permitió observar la organización espacial y localización de las empresas en los territorios escogidos. 


\section{Imagen 1: Aglomeración hotelera de Acapulco - Guerrero. 2017.}

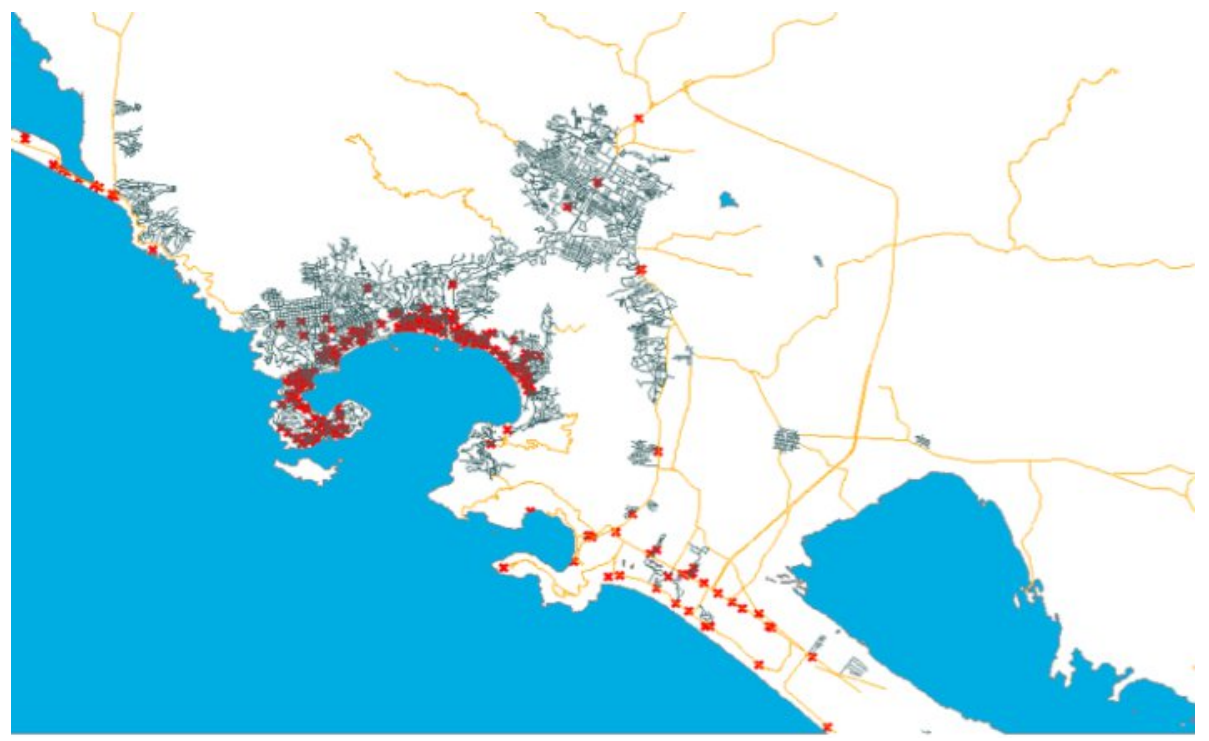

\section{Fuente: elaboración propia}

Aglomeración hotelera en Acapulco

La Imagen 1 evidencia que la principal aglomeración hotelera se ubica en las costas, principalmente en las playas donde se tiene accesibilidad para bañarse ya que el foco de atracción y aglomeración económica hotelera es la playa, las vistas y la bahía. En este sentido se genera una mutua y complementaria relación entre la disponibilidad de playa y la aglomeración de los hoteles. Lo anterior explica el crecimiento histórico de la aglomeración hotelera en la zona de la costa de Guerrero, especialmente en la zona de Acapulco que está estrechamente ligado al tipo de turismo que predomina en la ciudad, el cual es turismo de sol y playa.

Por otra parte podemos notar que en las zonas distantes de la principal aglomeración hay otras aglomeraciones hoteleras más pequeñas ubicadas a las salidas de la ciudad, los hoteles que aquí se encuentran son en su mayoría para uso local, razón por la cual se sitúan en zonas alejadas a las playas más importantes en cuanto a turismo para la ciudad, ya que el tipo de clientes que se hospedan en estos lugares por lo general no lo hacen motivados por el turismo de 
sol y playa. Sin embargo, esta aglomeración económica no se explica solo por el consumo local, ya que durante las temporadas bajas se nutren de este mercado pero en temporadas altas $y$ de mayor afluencia de turistas tienen la doble función, del consumo local y el consumo turístico. Es importante resaltar que el tipo de turistas que se hospedan en estos hoteles son por lo general nacionales que tienen bajos ingresos y deben ocupar un espacio, para este mercado ese espacio genera posibilidades de acercarse a la playa a un menor costo.

La aglomeración económica permite tener una oferta diversificada y eso genera sinergia entre los diversos oferentes de servicios turísticos. En el caso de Acapulco la ubicación de la costa es muy importante para comprender donde se encuentra la hotelería debido a que esta trata de estar lo más cerca de la playa ya que ofertan la cercanía al mar y la accesibilidad a la playa, ocasionando de este modo la aglomeración. Es importante resaltar que Las manchas urbanas en la costa tienen unas características interesantes, la reconstrucción de las zonas de Acapulco, esta genera la
Zona Tradicional, Zona dorada y Zona Diamante y cada una maneja su propio estándar y estratificación económica. Sin embargo, lo que pase en una zona no está aislado de lo que suceda en las demás y es aquí donde se ubica la mayor aglomeración de hoteles.

El océano pacifico donde pertenece Acapulco tienen características muy propias como que la playa es reducida, hay más quebradas, la arena es blanca y el agua cristalina, esto podría ser una ventaja comparativa que atraiga mayor turismo. Por esta razón es más densa la aglomeración ya que la dotación de playas no es tan grande y hay zonas de difícil accesibilidad.

Para Acapulco su principal mercado en cuanto al turismo es la Ciudad de México, el Estado de México y Toluca, esto se debe en parte a la cercanía entre estos lugares, el buen estado de las carreteras que los conectan con la ciudad y el clima cálido que durante todo el año permite que se pueda disfrutar a gusto de las playas. Estos turistas encuentran aquí un lugar para descansar, estar en la playa y divertirse por las noches en 
los diversos bares y antros que ofrece la ciudad. Pero no son solo estás las razones por las que llegan turistas hasta Acapulco ya que no es el mar el único factor de atracción, teniendo en cuenta que este se encuentra en todo el país y hay otras playas cerca a estos principales mercados, lo que hace a este destino interesante es que en él hay dotación de infraestructura y aglomeraciones turísticas, esto ha hecho que se mantenga un estatus importante y la aglomeración hotelera siga funcionando a lo largo de los años. Por lo tanto es importante

\section{Imagen 2: Aglomeración hotelera} de Acapulco - Guerrero. 2011.

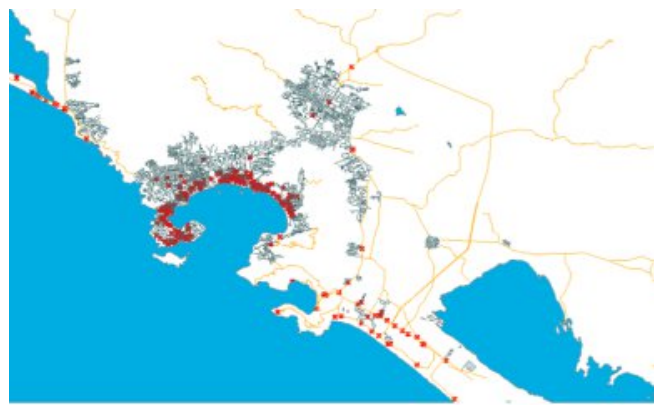

Fuente: elaboración propia que se diseñen políticas públicas que fomenten el atractivo de la ciudad, la preservación de los recursos naturales, la infraestructura y la seguridad tanto para habitantes como para turistas.

\section{Mirada retrospectiva a la aglomeración hotelera en Acapulco durante el periodo $2011-2016$}

Como lo evidencian las ilustraciones 2, 3 y 4 la aglomeración hotelera en Acapulco no ha cambiado mucho en los últimos años, en estos mapas se puede apreciar como

\section{Imagen 3: Aglomeración hotelera de Acapulco - Guerrero. 2015.}

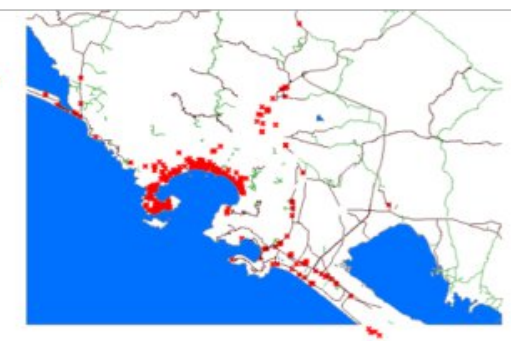

Fuente: elaboración propia

\section{Imagen 4: Aglomeración hotelera} de Acapulco - Guerrero. 2016.

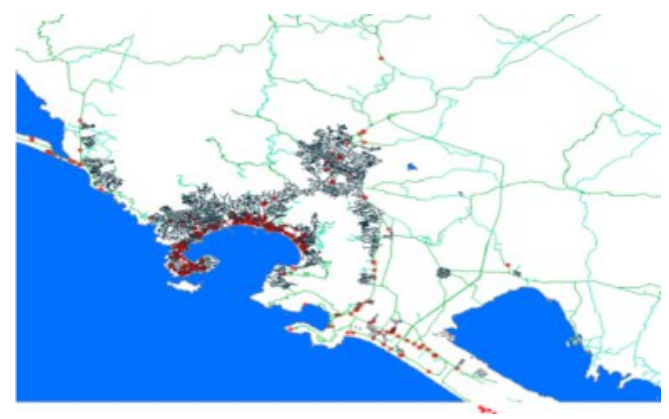

Fuente: elaboración propia 
desde 2011 los hoteles ya estaban ubicados en la zona costera debido a la cercanía a las mejores playas de la ciudad ya que el turismo de sol y playa es el que ofertan a sus clientes.

Análisis de la aglomeración hotelera en Boca del Río

La zona hotelera que se refleja aglomerada en este mapa (Imagen 5) es la mejor del estado de Veracruz, está ubicada a la cercanía de las mejores playas de Boca del Río y tiene la mayor dotación de infraestructura. Es importante tener en cuenta que lo que origina que se invierta en los bulevares y malecones y que nuevos hoteles se sigan instalando en una zona es la in- fraestructura hotelera con la que esta cuenta, lo anterior da pie a una paradoja en la cual los hoteles se van quedando en una zona y se les va invirtiendo ahí y se convierte en una sinergia, esto es lo que sucedió en Boca del Rio, donde los hoteles se aglomeraron en un lugar determinado y eso hizo que se invirtiera en mejorar y embellecer esta zona y atrajo a nuevos hoteles a instalarse ahí.

Las marcas rojas que representan los hoteles en el mapa se expanden notoriamente, lo que hace que la aglomeración en este lugar sea dispersa, pero no por eso no existe aglomeración ya que esta es

\section{Imagen 5: Aglomeración hotelera de Boca del Rio - Veracruz. 2017.}

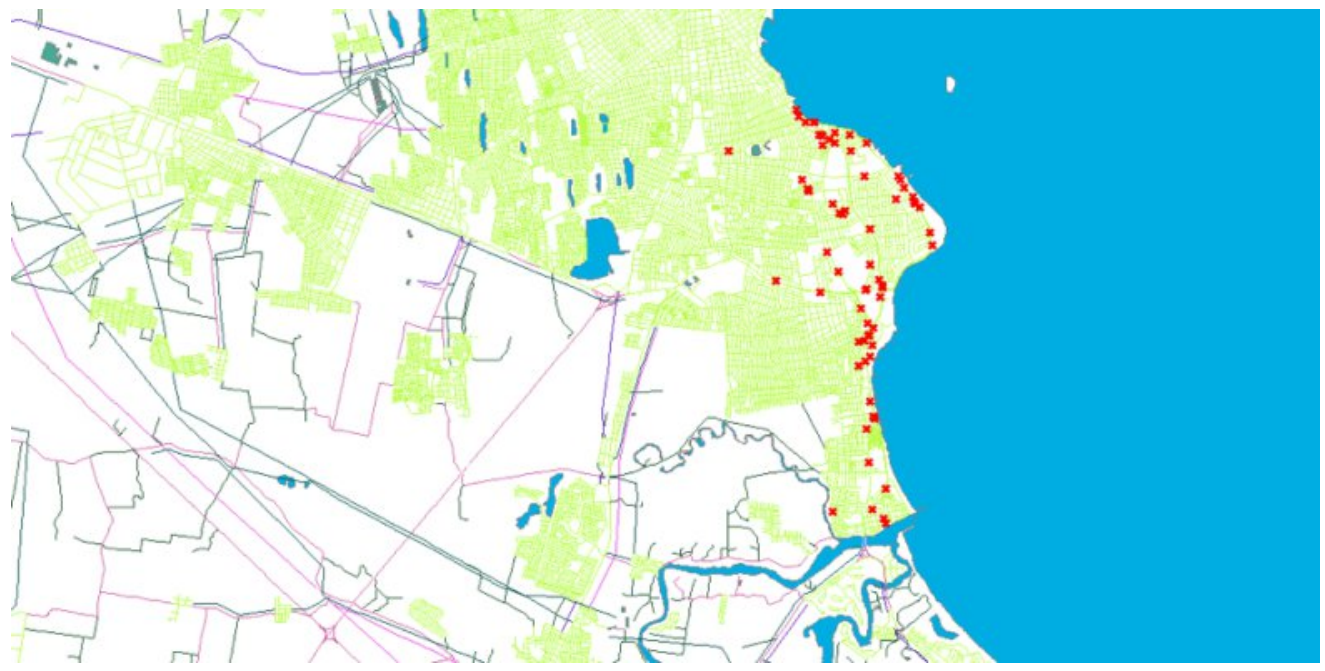

Fuente: elaboración propia 


\section{Imagen 6: Aglomeración hotelera} de Boca del Rio - Veracruz. 2011.

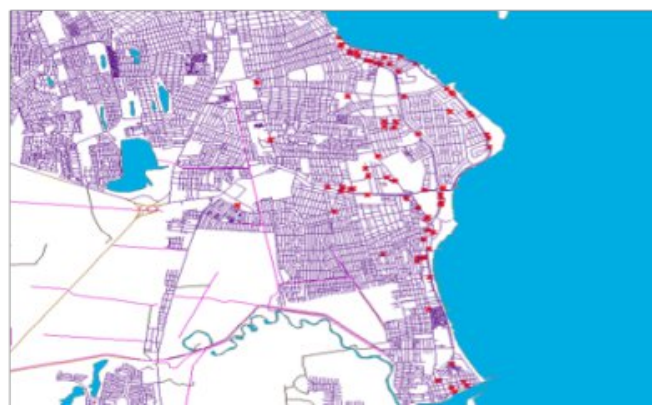

Fuente: elaboración propia
Imagen 7: Aglomeración hotelera de Boca del Rio - Veracruz. 2015.

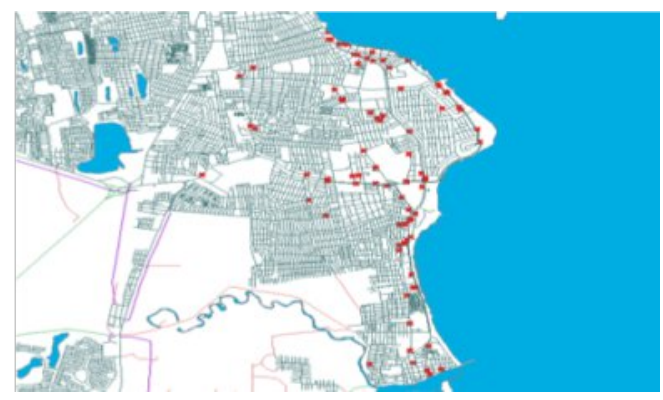

Fuente: elaboración propia extendida, es importante tener en cuenta que Boca del Rio está ubicado en el Golfo de México y la zona del golfo cuenta con playas más amplias y hay menos espacios de quebradas, esto incide en que la aglomeración extendida se dé debido a la amplitud de las playas que hacen que la aglomeración se ensanche a lo largo de los kilómetros de costa.

Todo lo anterior evidencia que invertir en infraestructura en las zonas de mayor aglomeración tiene un mejor efecto que en otras zonas a pesar de que el suelo sea un poco más costoso debido a la presión que la disponibilidad de piso hace en el precio del mismo y en los precios para generar hotelería, ya que generar nuevas empresas que fortalezcan el turismo como restauran- tes, bares, foros y teatros complementarán la oferta turística haciendo que esta aumente.

Por otra parte, se puede observar en el mapa que a diferencia de Acapulco los hoteles que están ubicados en Boca del Rio se encuentran aglomerados en una sola zona, esto se debe muy probablemente a que en este municipio se ha constituido un cluster turístico que organiza a todas las empresas hoteleras en una misma área geográfica.

\section{Mirada retrospectiva a la aglomeración hotelera en Bo- ca del Río durante el periodo $2011-2016$}

La aglomeración hotelera en Boca del Río aunque existe y ha existido, en los años 2011, 2015 y 2016 se nota más expandida e incluso se 
ven algunos hoteles más alejados de la zona más densa de la aglomeración en comparación con el mapa del año 2017 donde los hoteles están en una única zona, esto probablemente se debe a los esfuerzos que aún se siguen haciendo en este destino por consolidar el cluster turístico y tener un mayor orden con respecto a la organización del espacio y las empresas turísticas.

Imagen 8: Mapa de Centros Nocturnos, Bares, Cantinas y Similares en Acapulco.

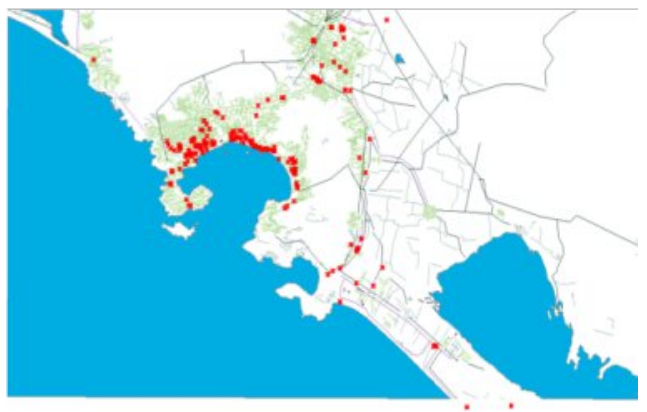

Fuente: elaboración propia

Imagen 10: Mapa de Restaurantes con Servicio de Preparación de Pescados y Marisco en Acapulco.

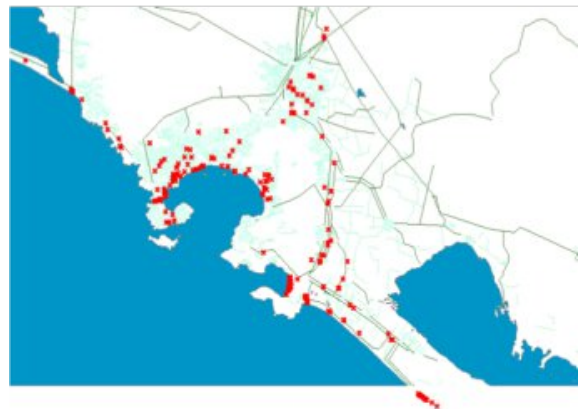

Fuente: elaboración propia
Otras aglomeraciones derivadas de la aglomeración hotelera en Acapulco y Boca del Río

En el caso de la aglomeración hotelera en Acapulco y Boca del Río, estas han generado una externalidad inmediata que son otras aglomeraciones que se enriquecen del sector hotelero pero que lo beneficia también, algunas de estas aglo-

Imagen 9: Mapa de Centros Nocturnos, Bares, Cantinas y Similares en Boca del Río.

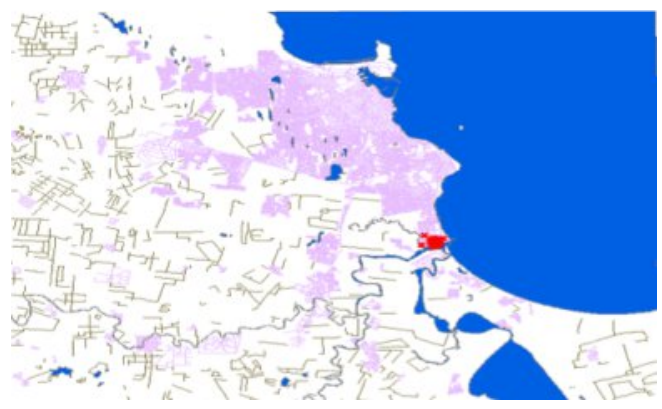

Fuente: elaboración propia

Imagen 11: Mapa de Restaurantes con Servicio de Preparación de Pescados y Marisco en Boca del Río.

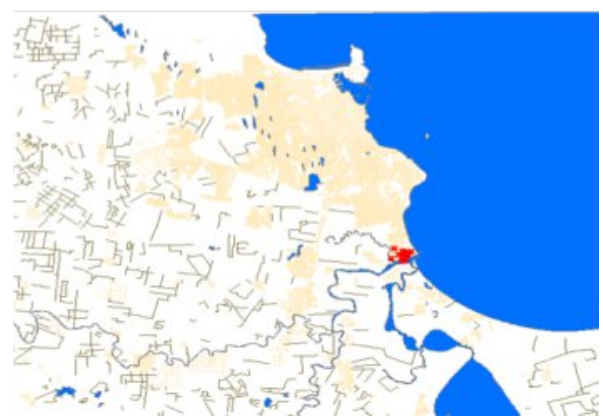

Fuente: elaboración propia 
meraciones son de centros nocturnos, bares, cantinas, similares y restaurantes con servicio de preparación de pescado y mariscos, este último por la cercanía a la playa que hace que el cliente por lo general prefiera este tipo de comida. En el caso de Acapulco y como lo muestra la Imagen 8 la aglomeración de centros nocturnos, se hace más densa en la costa donde su ubica la zona turística y la aglomeración hotelera principal; sin embargo hay oferta de este tipo de negocios alejadas de la aglomeración más grande y estas pueden ser de tipo cantinas destinadas en su mayoría al consumo local.

Por su parte la aglomeración de centros nocturnos y restaurantes en Boca del Río (Imagen 9 y 10) está ubicada en una única y misma zona geográfica muy cercana al área de aglomeración hotelera, estas dos aglomeraciones a diferencia de la hotelera son muy densificadas y es sencillo para el turista encontrar toda la oferta de este tipo de centros nocturnos y restaurantes debido a que son una única aglomeración. En Acapulco la oferta de restaurantes es más dispersa y mucho más amplia, en el mapa (Imagen 10) se puede ver tres grupos de aglomeraciones, la más grande de ellas ubicada en la bahía de la ciudad donde las playas brindan mayor accesibilidad para bañarse y donde se encuentra también la principal aglomeración hotelera; no obstante hay una segunda aglomeración igual de expandida pero que también se ubica cerca a la costa hacia Puerto del Marqués que es otra zona turística destacada de la ciudad y una tercera aglomeración alejada de las zonas turísticas.

Lo anterior evidencia que este tipo de ofertas solo se ubica en estos lugares de alta densidad. En este sentido, el mar se convierte en una excusa perfecta para que los turistas lleguen a este destino, pero influyen otros factores para que el turista decida regresar, por lo cual los hoteles no solo dependen del mar para mantenerse a flote en el mercado y hacer que su cliente regrese o hable bien del destino, sino también de las otras empresas que fomentan el turismo. Esto demuestra que no basta con mejorar solo el servicio que prestan los hoteles, es necesario también fortalecer la calidad del servicio que prestan los bares y los restaurantes ya que es- 
to hará que se genere un mejor atractivo turístico que beneficie a todos.

\section{Comentarios Finales}

Una de las características de la dinámica económica actual es la configuración de espacios productivos muy diferenciados, localizados en un grupo singular de ciudades y regiones de los países desarrollados y de los países en desarrollo donde se ubican grupos de empresas (Barquero, 2006). Un claro ejemplo de lo anterior radica en como la actividad económica en el mundo tiende a agruparse en ciudades específicas que les facilita el acceso a recursos y mercados necesarios para el desarrollo de una industria.

El documento señala que las empresas de un mismo sector económico e incluso industrias que no están relacionadas entre sí, suelen agruparse en una misma área geográfica por todos los beneficios que se derivan de esto. Algunas ventajas de las aglomeraciones económicas radican en la generación de economías de escala, efectos de red, mayor división $y$ especialización del trabajo, poder de negociación con proveedores, flujos de información entre las empresas y acceso a recursos y mercados; todo esto da lugar a una mejor eficiencia empresarial.

En este artículo se analizaron dos ciudades turísticas de México, cada una con un gran potencial que no ha sido explotado al máximo, razón por la cual no son tan reconocidos a nivel internacional; estos destinos son Acapulco y Boca del Río. Gracias a los datos ofrecidos por el INEGI en su Directorio Estadístico Nacional de Unidades Económicas se pudo observar como las teorías acerca de la aglomeración económica se hacen realidad en ambas ciudades donde la industria analizada, la hotelera, se ha ido agrupando en una misma zona geográfica dando lugar a una aglomeración.

Sin embargo, existen factores que no han permitido que la industria crezca y se fortalezca en ambos lugares, algunos de esos factores son la inseguridad, que se ha vuelto una barrera para que más turistas elijan estos destinos; La mala imagen generalizada dentro y fuera del país, no solo de ambos 
destinos como inseguros sino también por la contaminación gracias a drenajes en mal estado, la falta de plantas de tratamiento de aguas residuales que incide en que estas aguas se viertan en el mar y que existan pocas playas certificadas como limpias; y problemas con la infraestructura, que aunque hay dotación de esta, mucha de esa infraestructura es obsoleta. Todos estos aspectos negativos han opacado las muchas otras bondades que poseen ambos destinos, riquezas como sus legados culturales e históricos, sus magníficos recursos naturales, la calidez y familiaridad con que te recibe su gente y las fascinantes tradiciones que las caracterizan.

Para obtener beneficios que se derivan de las aglomeraciones económicas, no basta solo con ubicarse en una misma área geográfica, es necesario organizarse y trabajar de forma cooperativa por el impulso de la industria, el sector y el destino en general. Un claro ejemplo de cooperación son los distritos industriales que se caracterizan no solo por agruparse en un mismo espacio sino también por su sinergia que da lugar a una visión en conjunto que los hace trabajar de forma cooperativa no solo entre las empresas pertenecientes al distrito, sino también con otros sectores económicos, la sociedad, el gobierno y el medio ambiente; demostrando apego y amor por la ciudad, lo que los lleva a buscar no solo el éxito, el desarrollo y el crecimiento de las empresas sino del territorio que los ha acogido.

Las industrias hoteleras en Acapulco y Boca del Río deberían considerar organizarse bajo una visión similar a la de los distritos industriales, dándole prioridad a la lealtad, a generar innovación en la prestación del servicio, actuar de forma sinérgica y trabajar bajo estándares de calidad; es importante que estas industrias comprendan que para poder transformar la hotelería hay que empezar por transformar el entorno, y es necesario percatarse de que en un futuro la hotelería seguirá creciendo gracias a la transferencia generacional no solo del conocimiento y las practicas, sino también de la pasión por el turismo, sector del cual muchas familias en México, Acapulco y Boca del Río viven. 


\section{REFERENCIAS}

Alburquerque, F. (2006). CLUSTERS, TERRITORIO Y DESARROLLO EMPRESARIAL: DIFERENTES MODELOS DE ORGANIZACIÓN PRODUCTIVA. Cuarto Taller de la Red de Proyectos de Integración Productiva del Fondo Multilateral de Inversiones (MIF/FOMIN) , 3 - 4.

Barquero, A. V. (2006). Surgimiento y Transformación de Clusters y Milieus en los Procesos de Desarrollo. Eure, 77.

CONCANACO SERVYTUR. (2017). Boletín Turismo. México: Dirección de Turismo y Comercio Extererior.

Concanaco Servytur México. (2017). Indicadores de Guerrero. Obtenido de Concanaco.com.mx: http://www.concanaco.com.mx/documentos/indicadoresestados/Guerrero.pdf

DATATUR. (2017). Información Turística por Entidad Federativa. Obtenido de SECTUR: http://www.datatur.sectur.gob.mx/ITxEF/ITxEF_VER.aspx

Hernández, D. F. (2014). Las Economías de Aglomeración y el Empleo: Caso de Estudio el Veneto, Italia. Veracruz, México: MaJoMa Editorial y Editorial Lulú.

Instituto Nacional de Estadística y Geografía. (s.f.). INEGI. Obtenido de INEGI: http://www.inegi.org.mx/geo/contenidos/mapadigital/

Manrique, O. L. (2006). Fuentes de las Económias de Aglomeración: Una Revisión Bibliográfica. 55.

Quintar, A., \& Gatto, F. (1992). Distritos Industriales Italianos Experiencias y Aportes Para el Desarrollo de Políticas Industriales Locales. CEPAL, 11.

Rodríguez Domínguez, M. (2001). LA CREACIÓN DE CLUSTERS TURÍSTICOS COMO INSTRUMENTO PARA LA
MEJORA COMPETITIVA DE LOS DESTINOS: UNA APLICACIÓN A LAS RÍAS BAJAS GALLEGAS. Investigaciones Europeas de Dirección y Economía de la Empresa, 119.

Sagarpa, \& FAO. (2013). AGLOMERACIONES PRODUCTIVAS ("CLUSTERS"): UNA VÍA PARA IMPULSAR LA COMPETITIVIDAD DEL SECTOR AGROALIMENTARIO EN MÉXICO. México .

Secretaría de Turismo. (22 de Junio de 2017). El Momento Turístico Que Vive México, El Mejor Que Se Ha Vivido En Su Historia. Obtenido de gob.mx: https://www.gob.mx/sectur/prensa/el-momento-turistico-que-vive-mexico-el-mejor-que-se-ha-vivido-en-su-historia?idiom =es

Secretaría de Turismo. (08 de Febrero de 2018). Generó 1,990 Millones De Pesos De Derrama Económica Primer Fin De Semana Largo Del Año. Obtenido de gob.mx: https://www.gob.mx/sectur/prensa/genero-1-990-millones-de-pesos-dederrama-economica-primer-fin-de-semana-largo-del-ano?idiom=es

Secretaria de Turismo de México. (10 de Abril de 2016). gob.mx. Obtenido de gob.mx: https://www.gob.mx/sectur/prensa/turismo-factor-relevante-para-la-economia-mexicana-enrique-de-la-madrid

Secretaría de Turismo de México. (13 de Marzo de 2018). Panorama del Sector Turístico. Obtenido de Consejo de Promoción Turística de México: http://www.cptm.com.mx/panorama-delsector-turistico?language $=\mathrm{es}$

SECTUR. (28 de 04 de 2014). Acapulco. Obtenido de Gob.mx: http://www.sectur.gob.mx/programas/gestion-de-destinos/productos-turisticos/bloque-pacificoy-mar-de-cortes/acapulco/ 
Sectur, BBVA Data \& Analytics, BBVA Bancomer. (2015). Veracruz. Obtenido de Sectur: http://www.datatur.sectur.gob.mx/Documentos\%20Publicaciones/BIGDATA_Veracruz.pdf\#search=boc a \%20del\%20r\%C3\%AD\%C3\%B3

Sistema de Información de Estadísticas Turísticas - DATATUR. (2018). Empleo Turístico. Obtenido de Sectur: http://www.datatur.sectur.gob.mx/SitePages/ResultadosITET.aspx

Strange, W. C. (2005) Urban Agglomeration. New Palgrave Dictionary of Economics, 2da Edición, Macmillan.

World Tourism Organization. (2015). UNWTO Tourism Highlights. Obtenido de e-unwto.org: https://www.e-unwto.org/doi/pdf/10.18111/9789284416899 